\title{
Predictive analysis of labor productivity growth factors: regional aspects
}

\author{
Elena Kalabina*, and Svetlana Smirnykh \\ Ural State University of Economics, 8 Marta/Narodnoy voli Str., 62/45, 620144 Ekaterinburg, Russia
}

\begin{abstract}
The study is aimed at identifying predictors of labor productivity growth in Russian regions. To compile a primary set of predictors and establish the relationship between them, a contextual review of publications on the topic under study was carried out. The factors, that directly and indirectly affect the increase in labor productivity in the regions of Russia, include institutional conditions; investments in fixed assets; orientation of companies to the development of new markets and participation in export activities; research and development costs; technological and organizational innovation; investment in human capital. The theoretical foundations for the formation of effective incentives in the regions for changing the strategic behavior of companies that meet global technological and socio-economic challenges are formulated. The results of predictive analysis are the basis for building a model of system dynamics of relevant factors of growth in labor productivity in the regions.
\end{abstract}

\section{Introduction}

Increasing labor productivity is an important problem in the modern Russian economy. However, due to the complexity and multidimensionality of this process, there are different points of view regarding the level of labor productivity and the set of factors affecting its growth. Predictive analysis of factors contributing or limiting the growth of labor productivity is the basis for the development of a regional policy of socio-economic development.

The purpose of the study is to identify predictors and build a model of systemic dynamics of productivity growth in Russian regions.

Within the framework of this topic, the main object of study is the macroeconomic estimates of labor productivity in Russia. It is worth noting a very limited number of regional and microeconomic studies, which would comprehensively consider the factors affecting labor productivity. Microeconomic research is mainly focused on industrial companies, while other sectors of the economy (agriculture, construction, trade, non-market services, etc.) are often excluded from the analysis. However, the identification of factors contributing or limiting productivity growth, including taking into account regional and sectoral differences, is the basis for developing government support measures for companies.

* Corresponding author: kalabina@mail.ru 
The study aims to address the following conceptual issues:

- What are the predictors of labor productivity growth at the regional level and how are they interrelated?

- Which companies are drivers of increasing labor productivity in the region's economy?

- What are the resource opportunities of the region to stimulate the economic behavior of companies to increase labor productivity?

The main obstacles to the growth of labor productivity lie in the weak motivation and insufficient resources of enterprises for this, as well as in the high barriers to entry and exit to new markets.

Predictive analysis made it possible to identify direct and indirect factors in the growth of labor productivity in the region: institutional conditions; amount and dynamics of investments in fixed assets; orientation of companies to the development of new markets and participation in export activities; amount and dynamics of research and development costs; implementation of technological and organizational innovations; amount and dynamics of investments in human capital.

According to macroeconomic estimates, the Russian economy is characterized by a relatively low level of labor productivity, 2-3 times inferior in this respect to the economies of a number of industrially developed countries [1, 2]. Since the late 1990s, labor productivity in the Russian economy has been showing positive dynamics, but the lag in labor productivity from the leading countries has hardly changed [3].

Labor productivity growth in the Russian economy in the period 1999-2008 was provided mainly due to the total factor productivity - increasing the general technological level of companies and improving the organization of production. However, in recent years, the growth rate of labor productivity in the Russian economy has noticeably decreased, and its main driver is the increase in the capital-labor ratio [3].

Macroeconomic assessments indicate that the existing gap in labor productivity between Russia and the leading foreign economies is mainly due to the lower level of total factor productivity. Along with this, the contribution of human capital to Russia's lagging behind leading foreign countries in terms of labor productivity is very small [3].

There is a significant intra-industry differentiation of Russian companies in terms of labor productivity. For example, in the timber processing industry, the leading enterprises in terms of the average level of productivity are more than 8 times ahead of other companies in the industry. Actual growth in labor productivity and a strong interest in increasing it are characteristic of leading companies and large enterprises, which creates the preconditions for further strengthening of the intra-industry stratification of companies in terms of productivity [4].

The orientation of government support towards more efficient companies leads to an even greater gap between leaders and outsiders. In this regard, special instruments of regional policy are needed in relation to companies with low labor productivity and with weak incentives for its growth [5].

\section{Materials and methods}

The discussion about the feasibility of increasing labor productivity, the consequences of creating highly productive jobs and supporting employment in the Russian economy is being updated in the context of new industrialization. The state is called upon to play the leading role of a "regulator" of increasing labor productivity and stimulating the creation of high-performance jobs, but the reaction of enterprises to these measures has not been sufficiently studied. In academic circles and among practitioners, there is no common 
understanding of the category of "high-performance job (HPJ)", methods of calculating and assessing the scale of the intensity of creation and modernization.

Most of the theoretical and empirical studies in this area are devoted to the study of macroeconomic problems of employment and the analysis of the dynamics of total factor productivity at Russian enterprises. The shift in the focus of research from the macrolevel to the enterprise level is associated with the recognition of the qualitative heterogeneity of enterprises both in the economy as a whole and in individual regions. This actualizes the study of the processes of creating HPJ at the enterprise based on the combined accounting of their industry and regional affiliation in the digital economy. Thus, the development of the foundations and methodological tools for the choice of regional policy instruments that stimulate an increase in labor productivity by enterprises seem to be relevant.

In the economic theory of labor, it is postulated that technological progress, technological innovation and digitalization of the economy act as a driver of changes in the structure of jobs. Understanding the "quality" of a jobs, various combinations of such basic characteristics as the level of wages, professional preparedness and qualifications of workers, the following conceptual approaches to the evolution of the structure of workplaces are distinguished. According to the first approach - "continuous improvement" - the acceleration of technological progress shifts the structure of jobs in favor of highly skilled workers, squeezing the segment of "low-quality" jobs [6]. The second approach substantiates the "polarization" of the structure of jobs due to the displacement of routine monotonous work and the increasing concentration of "high-quality" and "low-quality" jobs [7].

Analysis of the implementation of scenarios for the evolution of jobs, carried out on the example of countries with sustainable economic development, showed their diversity and complexity $[8,9]$. The difference in national models of the evolution of the structure of jobs means that technological progress is not the only determinant of shifts in the structure of jobs, and significant cross-country differentiation is explained by the influence of specific institutional factors of each state and its structural policies.

The results of the analysis of models of the qualitative evolution of the structure of jobs in Russia (1998-2012), carried out by V. Gimpelson and R. Kapelyushnikov, confirmed the hypothesis of the dominance of the trend towards a progressive improvement in the structure of jobs in the Russian labor market [10]. At the same time, the main driving force behind structural changes, in their opinion, was not technical progress, but the restructuring of agriculture, the growing integration of the Russian economy into the world market, institutional changes, etc.

The growth drivers of aggregate labor productivity in Russia are the industries associated with the production of non-tradable goods (construction) and market services (retail, telecommunications, financial services), as well as mining. At the same time, the growth of informal employment reduces labor productivity in the Russian economy [11].

Despite the widespread use in political and socio-economic discussions of the term "high-performance job", its operationalization is still lacking. It should be noted that there are many scattered criteria for classifying jobs as highly productive: both quantitative and qualitative [12].

Applied research on the processes of creating and modernizing high-performance jobs in the Russian economy is aimed at defining and quantifying the HPJs, as well as an analysis of the sectoral and regional dynamics of the HPJs [13-14].

The goals and objectives, types and methods of implementing industrial policy in fundamental and applied economic research are actively discussed [15-17]. There are two large groups of instruments for the implementation of industrial policy:

- endowing enterprises with resources in various forms (granting grants, subsidizing loans, etc.); 
- creating the effect of "endowment" with resources, using the tools of economic regulation: tax holidays, the possibility of accelerated depreciation of equipment, etc. [16].

Statistical assessments of the influence of socio-economic and other characteristics of regions on the rates of their economic growth, including labor productivity and employment, are presented in the research by O. Demidova and D. Ivanov, N. N. Mikheeva and other authors [18, 4]. It has been proven that the level of socio-economic development, sectoral structure, as well as spatial effects affect the dynamics of labor productivity in the regions of the Russian Federation [19].

Thus, the analysis of the problems of stimulating the growth of labor productivity and "improving" the qualitative structure of workplaces revealed the fragmentation of studies on the justification of the choice of regional industrial policy instruments to stimulate the economic behavior of Russian enterprises to create HPJs in the context of new industrialization.

\section{Results and discussion}

As a conceptual approach to the identification of factors directly and / or indirectly affecting labor productivity, the following are highlighted: institutional conditions; amount and dynamics of investments in fixed assets; orientation of companies towards the development of new markets and participation in export activities; amount and dynamics of research and development costs; implementation of technological and organizational innovations; amount and dynamics of investments in human capital.

Modern theoretical studies prove a relatively large contribution of the institutional characteristics of the region to its economic dynamics in comparison with other groups of factors [20]. Institutional changes associated with the formation and development of institutions that provide conditions for increasing labor productivity are recognized by modern researchers as one of the key areas of transformation to ensure the growth of labor productivity in the region and an important component of success.

The main problems hindering the growth of labor productivity in the regional context are the lack of the necessary resources for enterprises:

- human (shortage in the market of specialists with the necessary qualifications);

- financial (the enterprise lacks the necessary funds, the difficulty of attracting external financing);

- limited opportunities to expand sales: relatively small capacity of the markets in which the company operates, high barriers to entry into new markets.

Entering new markets, as a rule, is associated with an increase in labor productivity, which is especially true for firms entering international and new regional markets. The introduction of new technologies by them is associated with diversification - not only geographical, but also commodity. The higher the degree of novelty of the products, the more profound restructuring is required at all levels of the company. The introduction of new goods for an enterprise is most often associated only with product innovations, new for Russia goods - simultaneously with product (service) and process innovations, new goods for the world - along with product (service), process and organizational innovations.

According to National Research University Higher School of Economics (NRU HSE) estimates, there are too few (less than 10\%) firms transforming the market (introducing new products and technologies, entering new markets) in Russian basic non-resource industries, and too many (one third) inert firms. In the long term, this can lead to an increase in the technological backwardness of the Russian economy [3].

In this regard, within the framework of the policy of increasing labor productivity, it is necessary to launch the processes of structural transformation at the industry level, 
including measures aimed at bringing not just individual product groups to export markets, but technologically related clusters of product groups.

Among exporters, companies that are both exporters and importers have higher productivity levels. Companies' access to imported technologies can be decisive for the export activities of high value added companies. In this regard, a set of measures is needed, aimed not only at supporting enterprises to enter foreign markets, but also at simplifying their access to the best foreign products (services), which have no analogues in Russia and which are not objects of import substitution policy.

Research and development often accompanies the development of the release of new products, an increase in the competitiveness of companies, but it is necessary to take into account the nonlinearity of such a relationship - R\&D becomes effective only when the intensity of research and development expenditures is high enough. Firms producing new products on a global scale, on average, are characterized by a much higher level of R\&D expenditures - about $3.5 \%$ of revenue, while for Russian companies mastering the production of new products, this figure is only $0.7 \%$ of revenue [21].

The main incentives for companies to innovate are the changing needs of customers, the practices of other firms and the tightening of technical regulation requirements, that is, channels related to market demands. For firms with positive dynamics of productivity, foreign competitors were much more often the example. This manifests the diversity of the influence of developed competition: this is not only pressure on firms to improve efficiency, but also a demonstration of effective development practices for them.

One of the areas of technological modernization of companies is the digitalization of their activities. According to the NRU HSE estimates, each enterprise uses certain digital technologies, with the most common cloud technologies and automated ERP and CRM systems [3]. The digital transformation of companies not only ensures higher current labor productivity, but is also a factor in its growth in the future.

At the company level, the following features of the growing differences in investment in human capital were found:

- Large companies invest more in education and professional development of employees than small ones;

- Leading companies in labor productivity more often hold mass events to improve the qualifications of their personnel.

At the regional level, we note signs of growing differences in the intensity of investment in human capital, depending on the level of development of Russian regions. In contrast to highly developed regions, companies in less developed regions are more likely to invest in education and training of employees. This is probably a consequence of the washing out of human capital from less developed regions [22].

In recent years, in the regional policy being implemented to stimulate the growth of labor productivity in the basic non-resource sectors, a significant emphasis has been placed on training employees of enterprises and the introduction of improving innovations in the organizational sphere. These are important areas, however, according to the research results, it was found that the main needs of companies to increase labor productivity are associated not so much with organizational as with technological innovations, as well as with the introduction of new equipment.

\section{Conclusions}

In the context of tough budgetary constraints during a pandemic, the question arises of what should be the set of measures of state support for companies that stimulate productivity growth in the region. In this case, the most important are not so much measures of targeted support of certain projects, companies and industries, but systemic actions aimed at 
developing a competitive environment, a favorable business climate and reducing barriers to entry and exit to markets. In the absence of such measures, directive "coercion" of companies to increase productivity can only lead to imitation of change.

As the analysis has shown, the overwhelming majority of companies with a high level of labor productivity are interested in increasing it. While among the "lagging" firms, approximately one in four does not consider the growth of labor productivity to be any priority. Lack of focus of companies on the growth of labor productivity is not always associated with the shortcomings of the external environment. A significant number of companies have no internal motivation for productivity growth, which indicates failures in the corporate governance system.

Therefore, the debatable question is whether government support should be focused on the most efficient locomotive companies, or, conversely, on enterprises that demonstrate a low level of labor productivity?

However, with any choice, it is important to take into account that for companies that are leading in terms of labor productivity, tax incentives for the use of new technologies and equipment, as well as government support for the introduction of digital technologies, and are more significant, while for "lagging" firms, first, it is necessary to reduce administrative barriers. The conclusions obtained in the course of the study justify the expansion of the tools for stimulating the economic behavior of enterprises for the growth of labor productivity.

\section{References}

1. A. A. Zajcev, Voprosy Ekonomiki, 9 (2016)

2. V. E. Kireev, Bulletin of the UrFU. Series: Economics and Management, 2 (2017)

3. I. Voskoboynikov, Sources of labor productivity growth in Russia after the shocks of 1998 and 2008 in the context of the COVID-19-related economic crisis (HSE, 2020)

4. N. N. Miheeva, Region: Economics and Sociology, 86 (2015)

5. E. V. Balatsky, N. A. Ekimova, Mir novoj ekonomiki, 13 (2019)

6. L. F. Katz, K. M. Murphy, Quarterly Journal of Economics, 107 (1992)

7. D. H. Autor, F. Levy, R. J. Murnane, Quarterly Journal of Economics, 118 (2003)

8. M. Goos, A. Manning, A. Salomon, American Economic Review, 99 (2009)

9. E.O. Wright, R. E. Dwyer, Socio-Economic Review, 1 (2003).

10. V. Gimpelson, R. Kapeliushnikov, Russian Journal of Economics, 2 (2016)

11. V. Gimpelson, R. Kapeliushnikov, Mobility and stability in the Russian labor market (HSE, 2017)

12. R. A. Dolzhenko, S. V. Lobova, Economy of the region, 15 (2019)

13. S. G. Kuznetsov, A. G. Korovkin, Scientific Articles: Institute of Economic Forecasting of the Russian Academy of Sciences, 13 (2015)

14. N. N. Volkova, E. I. Romanyuk, Bulletin of the Institute of economics of the RAS, 5 (2015).

15. B. V. Kuznetsov, Y. V. Simachev, Journal of the NEA, 22 (2014)

16. A. E. Shastitko, Journal of the NEA, 22 (2014)

17. J. Y. Lin, New Structural Economics: a Framework for Rethinking Development and Policy (2012)

18. O. A. Demidova, D. S. Ivanov, Economic Journal HSE, 20 (2016) 
19. A. N. Bufetova, Region: Economics and Sociology, 102 (2019)

20. D. S. Tereshchenko, Vestnik NSUEM, 3 (2016)

21. V. Golikova, K. Gonchar, B. Kuznetsov, Russian Management Journal, 10 (2012)

22. A. A. Yakovlev, Journal of the NEA, 36 (2017) 